\title{
30. DOWNHOLE MAGNETIC LOGGING IN SEDIMENTS DURING LEG 145: USEFULNESS AND MAGNETOSTRATIGRAPHIC INTERPRETATION OF THE LOGS AT SITE $84^{1}$
}

\author{
G. Dubuisson, ${ }^{2}$ J. Thibal, ${ }^{2}$ V. Barthès ${ }^{3}$ J. Pocachard,${ }^{3}$ and J.-P. Pozzi ${ }^{2}$
}

\begin{abstract}
Downhole magnetic logging of sediments was conducted at two sites during Ocean Drilling Program (ODP) Leg 145 in the North West Pacific Ocean. Two different tools were used: a total field magnetometer (nuclear resonance magnetometer tool) using the overhauser effect and a susceptibility magnetic tool, based on the mutual induction of two coils caused by the surrounding rock susceptibility. Both tools have been developed through a cooperation between Total, CEA-LETI (a division of the French Commissariat à l'Energie Atomique) and Ecole Normale Supérieure-Centre National de la Recherche Scientifique.

From the logs obtained at Sites 883 and 884 , we show that the tool reliability is very high, and that the discrepancies which occurred between two repeat runs of the same hole were mostly related to the limits of the logging unit (Site 883), or to problems caused by a failure of the heave compensator and bad hole conditions (Site 884 ).

The usefulness of the downhole susceptibility log is discussed. Compared to whole-core magnetic susceptibility (WCMS), the downhole susceptibility log is continuous and therefore provides information, regardless of recovery and coring strategy, down to the deepest level of the deepest hole. These characteristics of the susceptibility log allow a better constraint for the reconstruction of true thickness of the sedimentary pile relative to what is possible using only WCMS measurements.

Despite the technical problems encountered during the leg, we propose for Site 884 a magnetostratigraphic interpretation of the total induction magnetometer log down to $450 \mathrm{mbsf}$, which corresponds to an age of more than $8 \mathrm{Ma}$. This magnetostratigraphy derived from the log improves and completes the data obtained on board ship from measurement of whole-core remanent magnetization.
\end{abstract}

\section{INTRODUCTION: USEFULNESS OF MAGNETIC LOGGING FOR PALEOCEANOGRAPHY}

Downhole magnetic logging was conducted during Leg 145 of the Ocean Drilling Program (ODP) at Sites 883 and 884 , which are situated near the top and on the northern flank of Detroit Seamount, at the northern extremity of the Emperor seamount chain. Two different tools were run both in Hole 883F and in Hole 884E: a total induction magnetometer tool (nuclear resonance magnetometer tool, or NRMT) and a magnetic susceptibility tool (susceptibility magnetic tool, or SUMT). Both tools have been developed through a cooperation between Total, CEA-Leti (a division of the French Commissariat à l'Energie Atomique), and Ecole Normale Supérieure-Centre National de la Recherche Scientifique. These tools have now been combined into a single tool and is deployed by Schlumberger under the name of GHMT (Geological High-sensitivity Magnetic Tool).

The preliminary objectives when working on marine sediments for paleoceanographic reconstruction are to obtain: (1) a complete sediment section with an absolute depth reference; (2) a precise and complete time frame. It appeared, during Leg 145, that downhole magnetic logging of seep-sea sediments is interesting for both basic goals.

To get the best possible recovery, the advanced piston corer (APC) was used to refusal in most of the Leg 145 Holes (Rea, Basov, Janecek, Palmer-Julson, et al., 1993). In general, this gave very good recovery (sometimes over $100 \%$ compared with the drilled interval). However, there are numerous reasons for double coring zones and a gap between cores usually exists (Ruddiman et al., 1987; OPD, 1990). As these problems cannot be avoided, a minimum of two holes is made at each site. These holes are cored in such a way that a core break in one hole is located at a depth where a continuous section of

\footnotetext{
'Rea, D.K., Basov, L.A., Scholl, D.W., and Allan, J.F. (Eds.), 1995. Proc. ODP, Sci. Results, 145: College Station, TX (Ocean Drilling Program).

${ }^{2}$ Laboratoire de Géologie, Ecole Normale Supérieure, URA 1316 CNRS, 24 rue Lhomond, 75231 Paris cedex 05, France.

${ }^{3}$ LETI-DSYS-CEA (Technologies Avancées), CENG, 38054 Grenoble cedex 9. France.
}

core exists in the nearby hole, with a possible problem only if gaps between cores are too large. To core several holes at each site is time consuming, so one of the holes is often much shorter than the other one. Another limitation of this technique is that if a lack of recovery affects one hole because of local lithology, it is probable that it will affect both holes.

In order to obtain a complete lithological column, physical properties of the sediments are used to correlate the lithology from one hole to another and to identify coring irregularities such as gaps between cores and/or double coring. One of these physical parameters, Whole Core Magnetic Susceptibility (WCMS) is easy to record and varies strongly with sediment lithology. This method is used to correlate between cores from one hole to another in order to establish a "composite depth section," which is complete and continuous as long as a common gap is not encountered (Ruddiman, Sarnthein, Baldauf, et al, 1988; Mascle, Moore, et al., 1988; Backman, Duncan, et al., 1988; Cochran, Stow, et al., 1989; Prell, Niitsuma, et al., 1989; Peirce, Weissel, et al., 1989; Rangin, Silver, von Breymann, et al., 1990; and review and examples in Robinson, 1993). At Site 884, such a gap occurs slightly above $90 \mathrm{mbsf}$.

Downhole measurements are useful because they give a continuous record of a given parameter regardless of recovery. We will show how the downhole susceptibility logs can be correlated to WCMS well below 90 mbsf where the composite depth is lost (in Site 884) or when only one hole is available. The correlations can help to determine the composite depth.

One of the best methods for obtaining the second objective, formation of a good time reference, is by using paleomagnetic reversals. When the sedimentation is not continuous, however, or when drillinginduced core disturbance or slumping has occurred, this method alone cannot give reliable results. It must be complemented by biostratigraphy, which requires the presence of a characteristic fauna in order to derive absolute ages for datum. The two methods used together will give the best results, providing that the recovery is good. As an example of the possible problems that can occur, the lack of recovery around $90 \mathrm{mbsf}$ in all holes of Site 884 implied that the top of the Olduvai event has not been found. Furthermore, calculations of sedi- 
mentation and mass accumulation rates derived from the biomagnetostratigraphy will always depend on the accuracy of the real ("composite") depth. Once again, downhole magnetic measurements do not depend on recovery and, as they are continuous, they will provide a better approximation of the "true sub-bottom depth". We will also show in this paper the magnetostratigraphic interpretations of the magnetic logs from Site 884 and compare these with the results obtained on cores.

\section{METHODOLOGY}

\section{Tool Specifications}

The NRMT uses the overhauser effect to measure the intensity of the total induction. The tool consists of two parts: the downhole part and the surface assembly. The surface assembly is made up of the frequency meter, which converts the frequency signal to field values with a precision of $0.01 \mathrm{nT}$; it is connected to the Schlumberger logging unit. The downhole part is the tool itself contained in a ceramic and epoxyde housing. Nonmagnetic extension cartridges separate the tool from the supply unit and from the cable and/or other tools. Its upper temperature limit of operation is $125^{\circ} \mathrm{C}$, although a low-temperature version $\left(65^{\circ} \mathrm{C}\right)$ was deployed during Leg 145 because high temperatures were not expected. The operation speed is $1800 \mathrm{ft} / \mathrm{hr}(\sim 550 \mathrm{~m} / \mathrm{hr})$ with a data spacing of 5 or $15 \mathrm{~cm}$.

The SUMT is based on the mutual inductance between two coils that is caused by the surrounding rocks. The distance between the coils is $0.8 \mathrm{~m}$ and the excitation frequency is about $200 \mathrm{~Hz}$. The upper limit of operation is $125^{\circ} \mathrm{C}$. This tool is also separated from the supply unit and from other tools by a nonmagnetic extension cartridge. The logging speed is 3600 or $1800 \mathrm{ft} / \mathrm{hr}(\sim 1100-550 \mathrm{~m} / \mathrm{hr})$ with the same data spacing as the NRMT.

\section{Principles of Measurement: Extracting the Remanent Magnetization from the Total Induction and Susceptibility}

In a borehole, the total induction $\mathbf{B}$ depends on location (p) and time $(\mathrm{t})$ and is the sum of several contributions with different intensities and wavelengths (see complete discussion in Pozzi et al., 1993):

$$
\mathbf{B}(\mathrm{p}, \mathrm{t})=\mathbf{B r}(\mathrm{p})+\mathbf{B a}(\mathrm{p})+\mathbf{B} \mathbf{f}(\mathrm{p})+\mathbf{B} \mathbf{t}(\mathrm{p}, \mathrm{t})
$$

where $\mathbf{B r}(\mathrm{p})$ is the regular core-related induction, which is mainly dipolar. In a borehole, it represents the major contribution to the total induction, and its dipolar part can easily be removed as a linear function of the depth: $\mathbf{B r}(\mathrm{p})=\mathbf{B r}(0)+\mathrm{dBr} \cdot \mathrm{p}$. In the absence of any regional anomaly, $\mathrm{dBr} \sim 20 \mathrm{nT} / \mathrm{km}$.

$\mathbf{B a}(\mathrm{p})$ is the induction due to the local anomaly of the total field. It will reflect large-scale variations in both susceptibility and remanence of the surrounding rocks or more local perturbations such as the effect of a basaltic horst near the borehole, or the induction resulting from the hole casing used to prevent the upper part of the hole collapsing. The first type of anomaly will be seen as a long-distance source and will correspond to variations of the gradient of the field in the borehole. For example, a log recorded in the Paris Basin in the southern part of a large-scale magnetic anomaly shows a vertical gradient of $38 \mathrm{nT} / \mathrm{km}$, whereas the part related to the inner field $\mathrm{Br}$ is only $20 \mathrm{nT} / \mathrm{km}$ (Pozzi et al., 1993). More local variations can be replicated by one or several dipoles.

$\mathbf{B f}(\mathrm{p})$ is the induction due to the surrounding rocks and depends on contributions from both the remanence and susceptibility of the rocks: $\mathbf{B f}(\mathrm{p})=\mathbf{B} \mathbf{f}_{\mathrm{r}}(\mathrm{p})+\mathbf{B} \mathbf{f}_{\mathrm{j}}(\mathrm{p})=\mathbf{B} \mathbf{f}_{\mathbf{r}}(\mathrm{p})+\mathrm{k}(\mathrm{p}) \mathbf{H}$, with $\mathbf{B} \mathbf{f}_{\mathbf{r}}$ and $\mathbf{B} \mathbf{f}_{\mathrm{i}}$ the induction related to the rocks' remanent and induced magnetization, $\mathrm{k}$ the susceptibility of the rocks, and $\mathbf{H}$ the Earth's field.

$\mathbf{B t}(\mathrm{p}, \mathrm{t})$ is the induction due to the transient variations of the Earth's field and thus depends on both ( $\mathrm{p}$ ) and ( $\mathrm{t}$ ). On land it can best be estimated by using a reference tool at the surface with the same sensor as the one enclosed in the tool. At sea this method is not possible, and the only way to reduce the temporal variations is to use a repeat section of the magnetometer log. Indeed, if we do not consider the possible depth errors, the only difference between the two passes will be linked to $\mathbf{B t}(\mathrm{p}, \mathrm{t})$. Because seawater is conductive, it will act as a filter. For a water depth greater than $200 \mathrm{~m}$, the only temporal variations that will still affect the downhole sensor will correspond to variations on the scale of a meter or more, considering the logging speed (Barthès, 1990).

We are interested in finding $\mathbf{B f}(\mathrm{p})$, the induction due to the sediments surrounding the borehole. First, we must estimate $\mathbf{B t}(\mathrm{p}, \mathrm{t})$, using the repeat section. and, second, the other components $\operatorname{Br}(\mathrm{p})$ and $\mathbf{B a}(\mathrm{p})$ then will be removed as a whole.

Once $\mathbf{B f}(p)$ is isolated from the other component of $\mathbf{B}(\mathrm{p}, \mathrm{t})$, we can use the susceptibility record to isolate the remanent magnetization Bf $_{\mathbf{r}}$ (p) (Barthès, 1990; Pozzi et al., 1993):

$$
\begin{aligned}
& \mathrm{NRMT}=\mathrm{B}_{0} / 2 \cdot\left(1-\sin ^{2} \mathrm{I}\right) \mathrm{R} 1 * \mathrm{k}+\mathrm{R} 1 * \mathbf{B f}_{\mathrm{r}} \\
& \text { with } \mathbf{B} \mathbf{f}_{\mathbf{r}}=\mu \mathrm{o} / 2(\cos \mathrm{I}, 0, \sin \mathrm{I}) \mid \begin{array}{r}
\mathrm{Jf}_{\mathrm{r}} \mathrm{x} \\
\mathrm{Jf}_{\mathrm{r}} \mathrm{y} \\
-2 \mathrm{Jf}_{\mathrm{r}} \mathrm{z}
\end{array} \\
& \text { SUMT }=\text { R2 } * \mathrm{k}
\end{aligned}
$$

where $B_{0}$ is the intensity and $\mathrm{I}$ is the inclination of the induction $\mathbf{B r}$ $+\mathrm{Ba}, \mu 0$ is the permeability of vacuum, $\mathrm{k}$ is the rock susceptibility, $\mathrm{Jf}_{\mathrm{r}}$ the remanent magnetization of the rocks and, R1 and R2 the response of the NRMT and the SUMT probes respectively.

\section{Log Quality and Technical Limitations}

The quality of a log recorded at sea depends on certain conditions: (1) tool reliability and (2) quality of the depth estimates given by the logging unit. The depth estimates are based on the length of cable advanced and on the way for which ship heave is compensated. We will first present data from Site 883, where the heave compensator was working, but where a lost bottom assembly in a nearby hole compromised the total induction $\log$. Then we will present the induction $\log$ from Site 884, where the heave compensator was not working, and where a collapse of the bottom of the hole led to some problems.

Figure 1 presents the results from the NRMT tool for Hole 883F. On the left, the two logs (runs 1 and 2) are shown with a scale shift of $20 \mathrm{nT}$, for a $200-\mathrm{m}$ interval. The BL values are a rough estimation of $\mathrm{Bf}$ and have been obtained by subtracting from the measured induction the effect of the dipolar part of $\mathrm{Br}$, and a rough estimation of $\mathrm{Ba}$ assumed here to be a constant. On this large scale (full range is $80 \mathrm{nT}$ ) it can be seen that both logs are very well correlated. The right panel of Figure 1 shows the difference between the two logs (full range is $24 \mathrm{nT}$ ). This difference will be related to the transient variations in the earth's field or to errors of measurement. The average difference for that depth interval ( $400-600 \mathrm{mbsf})$ is between 4.5 and $3 \mathrm{nT}$, slightly decreasing from top to bottom. This average difference is due to the transient variations of the earth's field. On the other hand, the high amplitude/high frequency variations of this difference cannot be due to variations in the earth's field because the measurements were done under $>3,000 \mathrm{~m}$ of conductive seawater. The variations are related to errors of measurement, i.e., for the same depth the value measured is not the same for the two passes. From the analysis of the difference between these two signals, it can be seen that they nearly always occur when the variations of the induction with depth are high, in a zone of high gradient. Furthermore, the difference BL1 - BL2 shows, for a single increase or decrease of the induction, a double peak signature indicating that the errors are mostly due to slight errors in the determination of the depth given by the logging unit. In other words, two data located at the same theoretical depth are made at a slightly 
BL1 (nT,run1)

$\mathrm{BL} 2(\mathrm{z})-\mathrm{BL} 1(\mathrm{z})$

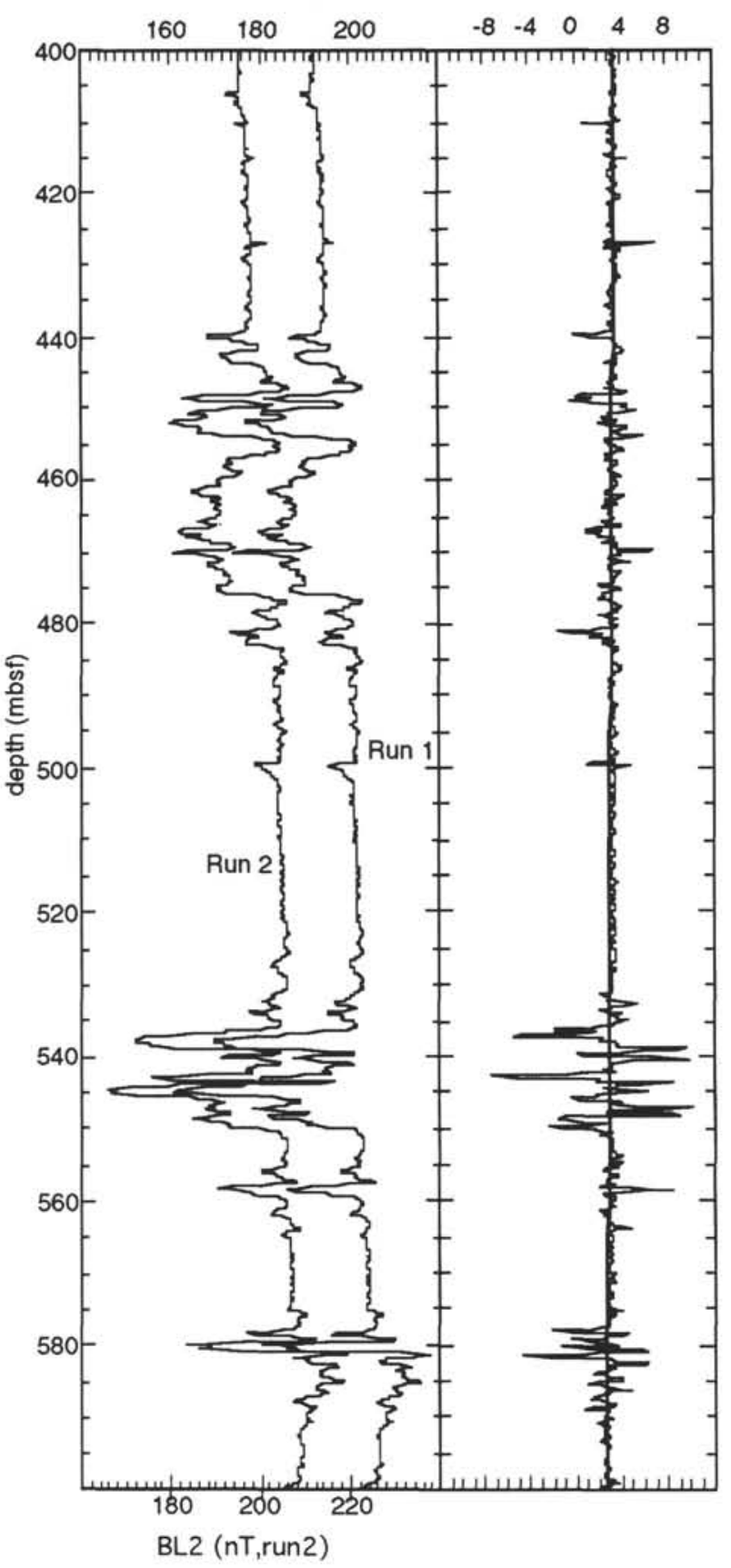

Figure 1. Induction logs from Site 883. The left panel contains a detail of runs 1 and 2 between 400 and 600 mbsf, minus the dipolar part of the induction, and a rough estimation of the regional anomaly (full scale is $80 \mathrm{nT}$ with a scale shift of $20 \mathrm{nT}$ between the two runs). The right panel shows the difference between the two runs (full scale is $24 \mathrm{nT}$ ).

different true depth, so the measured induction is also slightly different. This difference is related to the local gradient of the induction.

Figure 2 shows the same type of information for the SUMT as was shown in Fig. 1 for NMRT. On the left, the first susceptibility log, and the partial repeat section (runs 1 and 2), are shown with a $100 \mathrm{ppm}$ (part per million $\sim 10^{-6} \mathrm{SI}$ ) scale shift, the full scale deflection being 400 $\mathrm{ppm}$. On this large scale, the very good correlation between the two runs can be seen clearly. The right panel of Figure 2 shows the difference between the two runs with a total scale range of $250 \mathrm{ppm}$. The

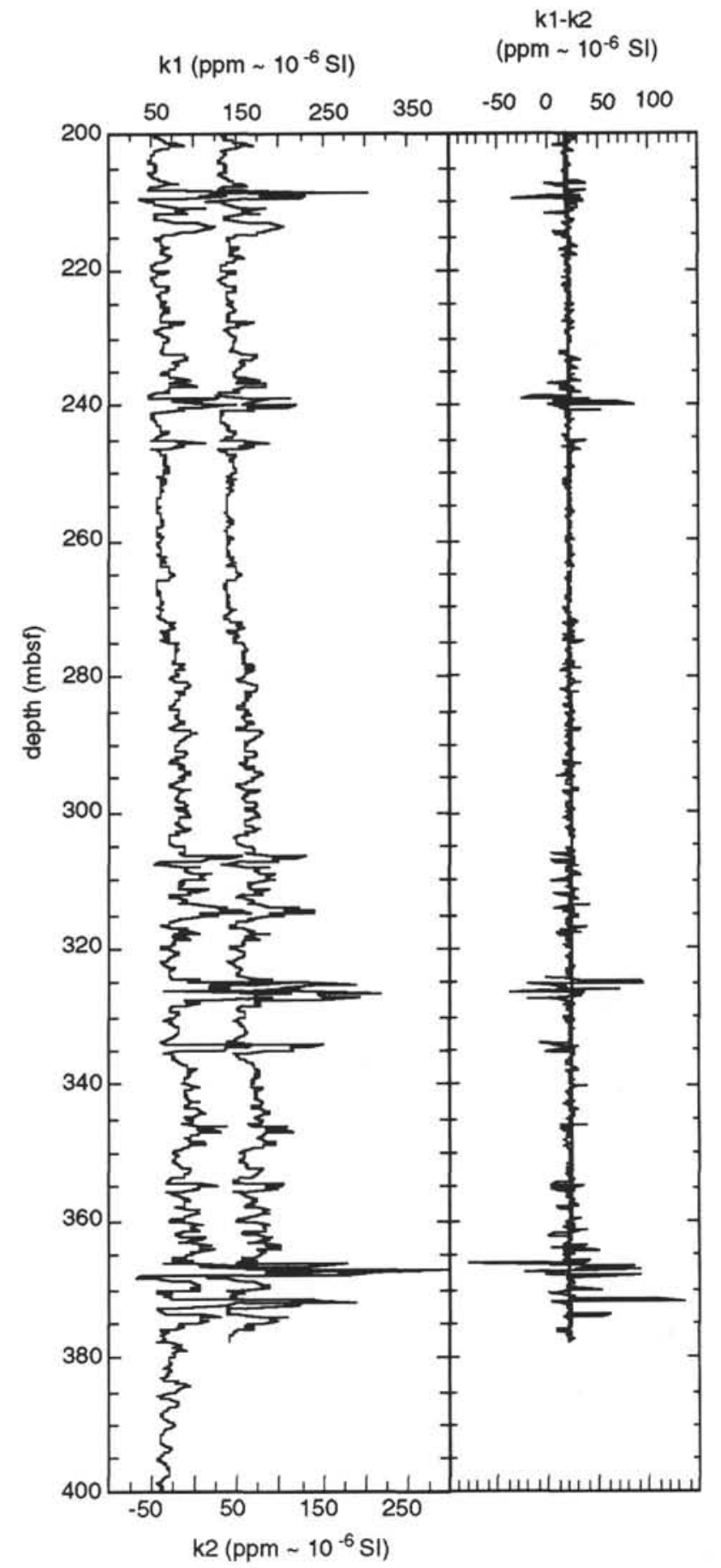

Figure 2. Susceptibility logs from Site 883. On the left is a detail of runs 1 and 2 between 200 and 400 mbsf (full scale is $400 \mathrm{ppm}$ with a scale shift of 100 ppm between the two runs). On the right is the difference between the two runs (full scale is $250 \mathrm{ppm}$ ).

average difference between the two logs is due to the effect of temperature variations on the electronics. Because temperature is measured at both the exciting and receiving coil for each susceptibility measurement, the difference correction can easily be applied knowing the thermal drift of the tool. Once again, the sharp peaks are related to measurement errors, and show the same characteristics as for the magnetometer tool: they appear in zones of high-susceptibility gradients and show a signature typical of slight depth determination errors.

Figures 1 and 2 show that when logging in an oceanic environment, slight depth errors cannot be avoided even when the weather is 
fair and the heave compensator is working. These errors are mostly the technical limits of the logging system.

During the logging operations at Site 884, the bottom of the hole was collapsing, and the heave compensator was not working. Figure 3, right panel, shows the first NRMT run (BL1 as defined for Fig. 1) as well as the difference BL1 - BL2 between the two runs. Figure 3, left panel, shows three expanded views of the two runs shown at right. Before the beginning of the first NRMT log, the bottom of the hole was reached with the tool well before its originally drilled depth. This was because the bottom of the hole was collapsing. The tool was then lifted about $10 \mathrm{~m}$ and held there for about $30 \mathrm{~min}$, while we tried to get the heave compensator working. As this was not possible, the first uplog was made without it (run 1). When the tool was sent down for the second run, the bottom of the hole was found to be higher than the base of the first run; thus, the hole was still collapsing. After a very short time, the second NRMT log was made, again without the heave compensator. Figure 3 shows that the differences between the two logs are much greater than for Site 883. Furthermore, correlations between intervals of high differences and of high gradient of BL1 are not as clear as they were at Site 883 . The three close-ups of the two runs on the left side of Figure 3 show that there is a systematic depth difference between the two logs: run 2 shows the same pattern of magnetic susceptibility variations as observed in run 1 at a lower depth below sea floor. Another feature that can be seen in Figure 3, left panels, is that the depth difference between the two runs increases with depth downhole. This is due to the cable slowly recovering its normal elongation under tension. According to Schlumberger France (pers. comm., 1992), the elongation of the cable is on the order of 1 $\mathrm{m} / 1000 \mathrm{~m}$ of cable. As the depth difference at the base of the log is

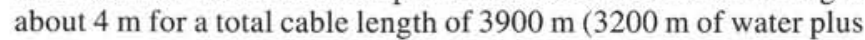
$\sim 700 \mathrm{~m}$ in the hole below sea floor) this order of magnitude of cable elongation is in agreement with the offsetting of the logs shown in Figure 3 left. The depth given by the second run is thus a minimum, but it is quite easy to evaluate the true depth of this run by using the $\log$ of the first run. Another feature shown in Figure 3 is the effect of uncompensated heave on the logs. It is not always easy to recognize some pattern of total induction variations in both logs because their features are deformed. This is due to the fact that, for any given feature of the profile, the tool has a varying speed with which it logs that interval of the hole, and there is thus a slight error in the depth of the measurement, which leads to minor differences in the pattern of the resulting total induction profile for each run. In this case, without the heave compensator, the vertical resolution is about $1 \mathrm{~m}$. A similar resolution is also observed for the susceptibility log (Rea, Basov, Janecek, Palmer-Julson, et al., 1993).

Although there is no other way to interpret the data, the problems of depth mismatches between logs, related to the tension of the logging cable, were surprising. The reason for this problem on Leg 145 was probably that each of the magnetic tools used during Leg 145 was run alone. As the magnetic tools used on Leg 145 are much lighter than a full tool string, such as the ones used for geophysical logging, for instance, it probably took much longer to put all the cable in tension. Also, because we did a full repeat section in the case of the magnetometer tool, this allowed us to compare two sets of data in order to provide evidence that the problem exists.

\section{THE USE OF DOWNHOLE SUSCEPTIBILITY LOGS TO EVALUATE THE TRUE THICKNESS OF THE SEDIMENTARY PILE}

One of the main problems during sedimentary logs is to achieve good recovery in order to restore the sedimentary pile to its true thickness. This is necessary in order to calculate rates of sedimentation or mass accumulation from bio- or magnetostratigraphy.

As stated above, gaps may occur between two successive cores in a sequence. To avoid this problem, two holes are drilled so that by measuring physical parameters such as magnetic susceptibility in each hole, it is possible to correlate between holes and reconstruct the true thickness of the sedimentary pile. Numerous workers have, since ODP Leg 108 (Bloemendal et al., 1988, 1989) developed a routine procedure on all ODP legs to obtain these results from whole core magnetic susceptibility (see, for example, Ruddiman, Sarnthein, Baldauf, et al, 1988; Mascle, Moore, et al., 1988; Backman, Duncan, et al., 1988; Cochran, Stow, et al., 1989; Prell, Niitsuma, et al., 1989; Peirce, Weissel et al., 1989; Rangin, Silver, von Breymann, et al., 1990). It is far beyond the scope of this paper to present an extensive review of this technique, which can be found with the appropriate references in Robinson (1993). We will present one example only from Leg 145 Site 884 to show how a downhole susceptibility log can be useful for such a study and then present two examples of the downhole magnetic susceptibility data compared with whole core magnetic susceptibility data.

Figure 4 shows how, by coring with overlapping core limits, it is possible to reconstruct the full sedimentary sequence by dovetailing a composite section from both holes (composite depth). Figure 4, left panel, shows the first four cores from Hole 884B and the whole core susceptibility data recorded on board ship with the Bartington MS2 meter. The central plot in Figure 4 shows the first three cores from Hole $884 \mathrm{C}$ and the whole core susceptibility profiles of these cores. On the right panel of Figure 4 is shown the composite susceptibility profile plotted on the composite depth scale with the source of the susceptibility record indicated $(\mathrm{B}=\mathrm{Hole} 884 \mathrm{~B} ; \mathrm{C}=\mathrm{Hole} 884 \mathrm{C}$ ). If a downhole susceptibility logging tool has the same response and data spacing as the whole core magnetic susceptibility logging system used on board, the log would be identical to the composite susceptibility profile obtained by dovetailing magnetic susceptibility data from both holes.

From the susceptibility profiles in Figure 4, we can deduce that a $10-\mathrm{cm}$ gap exists at the top of Core $145-884 \mathrm{~B}-1 \mathrm{H}$ relative to Core $145-884 \mathrm{C}-1 \mathrm{H}$. Because Core $145-884 \mathrm{~B}-1 \mathrm{H}$ is continuous, when the core break between Cores $145-884 \mathrm{C}-1 \mathrm{H}$ and $145-884 \mathrm{C}-2 \mathrm{H}$ occurs, the lack of recovery can be estimated by correlating some characteristic features of the susceptibility profile of $884 \mathrm{~B}$ with the same features in the profile of $884 \mathrm{C}$ above and below the core break (Fig. 4; correlation lines). This procedure can also be repeated for the $1 \mathrm{H} / 2 \mathrm{H}$ and $2 \mathrm{H} / 3 \mathrm{H}$ core breaks of Hole $884 \mathrm{~B}$, and for the $2 \mathrm{H} / 3 \mathrm{H}$ break of Hole $884 \mathrm{C}$. By using only the continuous parts of the susceptibility curves from both Holes $884 \mathrm{~B}$ and $884 \mathrm{C}$ (Fig. 4), it is possible to reconstruct the complete section.

In this example we have assumed that Hole $884 \mathrm{C}$ is only three cores deep, in order to show how the composite depth obtained from two holes is lost below the bottom of the shallowest hole. In the example shown in Figure 4, we have no data to estimate the possible lack of recovery between Cores 145-884B-3H and 145-884B-4H. In such a case, a downhole susceptibility $\log$ would be useful. One aspect of the data shown in Figure 4 that must be emphasized is that, even for nearby holes (Holes $884 \mathrm{~B}$ and $884 \mathrm{C}$ are only $20 \mathrm{~m}$ apart), the susceptibility signal can be slightly different because of local lateral variations in the composition of the sediment (e.g., Fig. 4; highlighted intervals) with local ash horizons and more or less gradational upper limits of the ash layers as observed on board ship by the scientific party.

As stated above, one limit of this method is the length of the shallowest hole; another is that if a recovery gap is common to both holes, then the composite depth is lost. For Site 884, it was not possible to compile a composite depth section older than the top of the Olduvai event (1.757 Ma; Cande and Kent, 1992) because there is a common gap in Holes 884B and $884 \mathrm{C}$ at that level (Cores 145-884B$12 \mathrm{X}$ and $145-884 \mathrm{C}-11 \mathrm{X})$. When susceptibility is measured downhole these two limitations are avoided as logging is continuous. Thus, if the susceptibility tool is precise enough to allow good correlations between core and log measurements, it is possible to give an "absolute depth" to all the cores from the site and the log will provide directly the true (composite) depth for the sequence. However, some technical limitations do exist. It is often necessary to put a casing in the upper- 


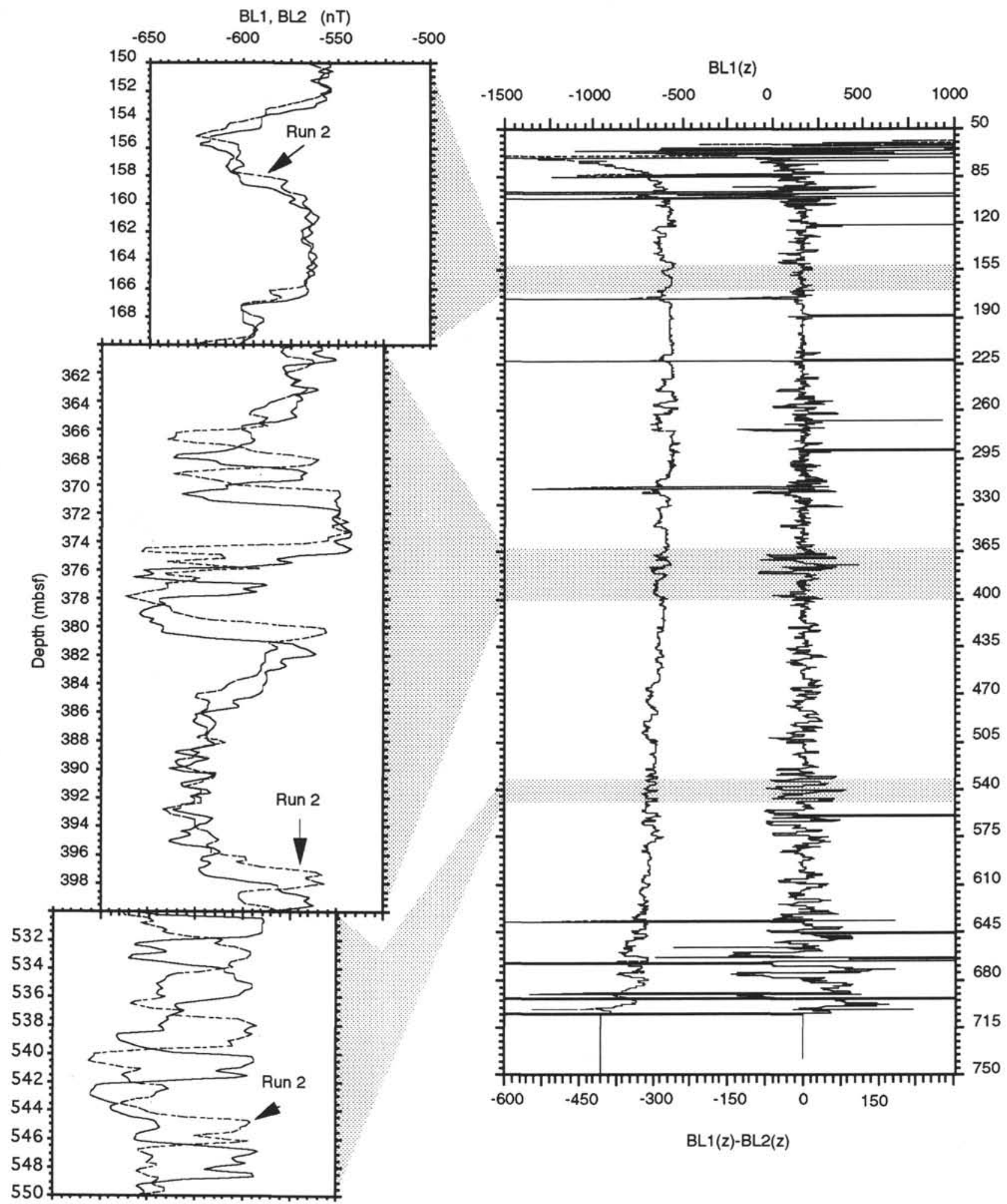

Figure 3. Induction $\log$ from Site 884 . On the right is the first run (full scale is $2500 \mathrm{nT}$ ) and the difference between the two runs (full scale is $900 \mathrm{nT}$ ). On the left are three close ups of the two runs to clarify the high difference between them (full scale is $150 \mathrm{nT}$ ).

most part of the hole in order to prevent water-rich sediments from collapsing, and it is not possible to make downhole susceptibility measurements in this part of the hole. Another limitation is the accuracy of the logging depth.

Figure 5 shows an example of shipboard whole core magnetic susceptibility to downhole magnetic susceptibility log correlation for
Site 884 between 450 and 530 mbsf, a depth where only one cored hole $(884 \mathrm{~B})$ is available. Downhole log data from Hole $884 \mathrm{E}$ are shown on the left and whole-core data on the right, with the location of the core and an indication of the recovery in the shaded column. It can be seen that the recovery in this zone is very good, with some problems for Cores 145-884B-52X and 145-884B-55X. From core 


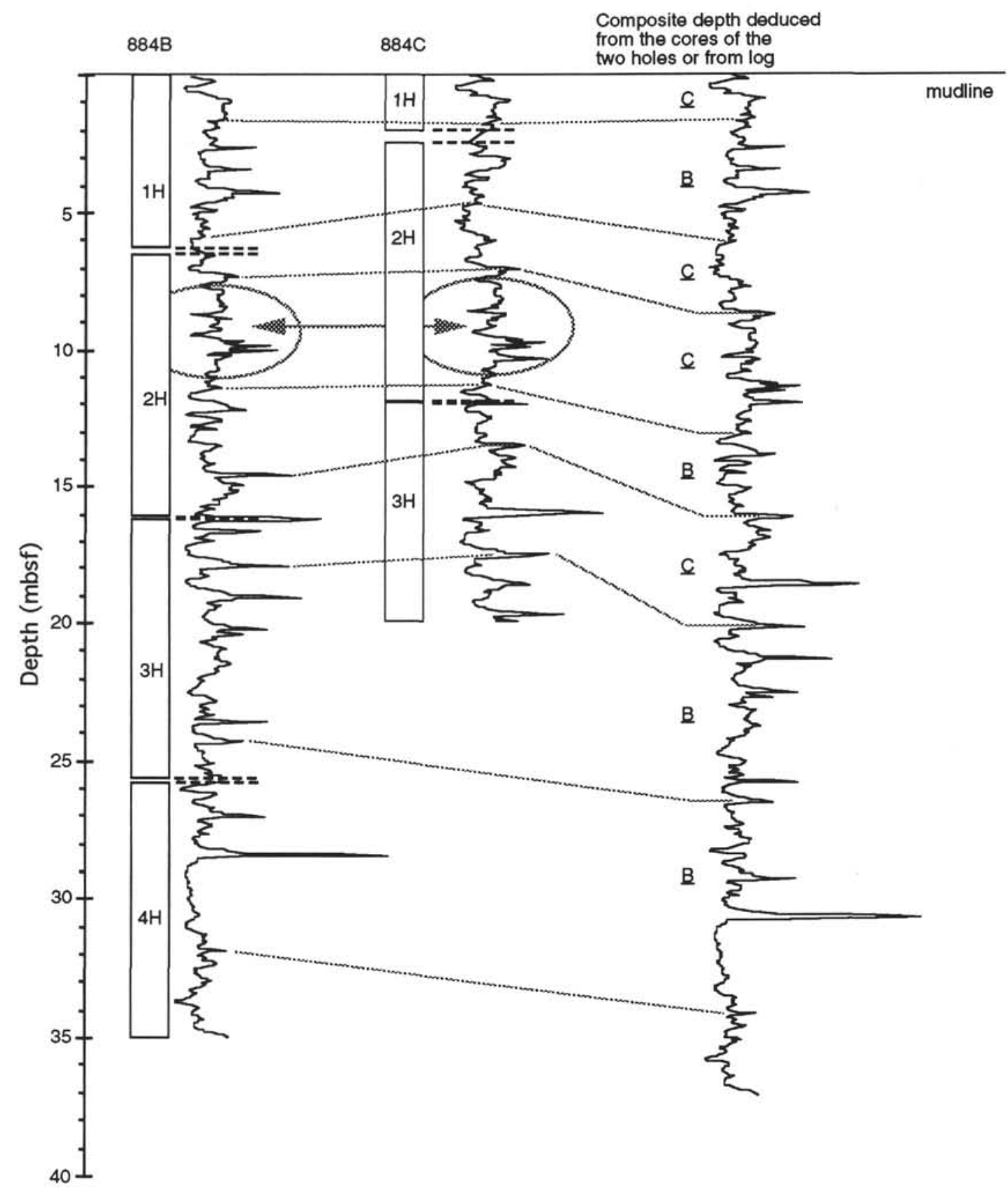

Figure 4. Correlation of susceptibility records for Site 884. The location and the susceptibility shown were measured on the first four cores of Hole $884 \mathrm{~B}$ and on the first three cores of Hole $884 \mathrm{C}$. To the right is shown the susceptibility record based on the continuous parts of both holes with the hole letters used as references. The correlation between the susceptibility records is drawn. The two circles linked with an arrow show the lateral variations in susceptibility for two nearby holes (20 $\mathrm{m}$ apart) and for two continuous records.

photography, it is seen that Core $145-884 \mathrm{~B}-52 \mathrm{X}$ is complete (Rea, Basov, Janecek, Palmer-Julson, et al., 1993), and the core description indicates some moderate disturbance (i.e. "bedding contacts are slightly bent"). Susceptibility measurements are available for only the first four sections. From core photography, no reason for this lack of data can be seen, which may be refated to problems with the MST track that occurred during the leg. Indeed, all of Core 145-884B-52X was measured with the pass-through cryogenic magnetometer of the JOIDES Resolution. As for Core 145-884B-55X, photography also shows that it is complete although the extent of drilling disturbance is much greater (Rea, Basov, Janecek, Palmer-Julson, et al., 1993). Only part of this core was subjected to measurements of remanent magnetization because of drilling disturbance, and susceptibility was only measured on Sections 1 to 5 , the latter section being shorter than normal. The parts of these two cores where susceptibility measurements are available are indicated by the lighter shading in Figure 5 .

It can be seen in Figure 5 that the susceptibility signal from cores and from downhole measurements show the same general trends but also show differences at the short wavelengths. This is related to differences in the volume of rock investigated by each of the sensors. On board ship, the MST track makes a measurement at $5 \mathrm{~cm}$ intervals, each measurement sensing a few $\mathrm{cm}^{3}$ of sediment. In the hole, the susceptibility tool also makes measurements at 5 -cm intervals but each measurement is sensing a few cubic meters of sediment. The maximum effect on the tool sensor will correspond to sediments located at the same depth as the sensor near the wall of the hole. 


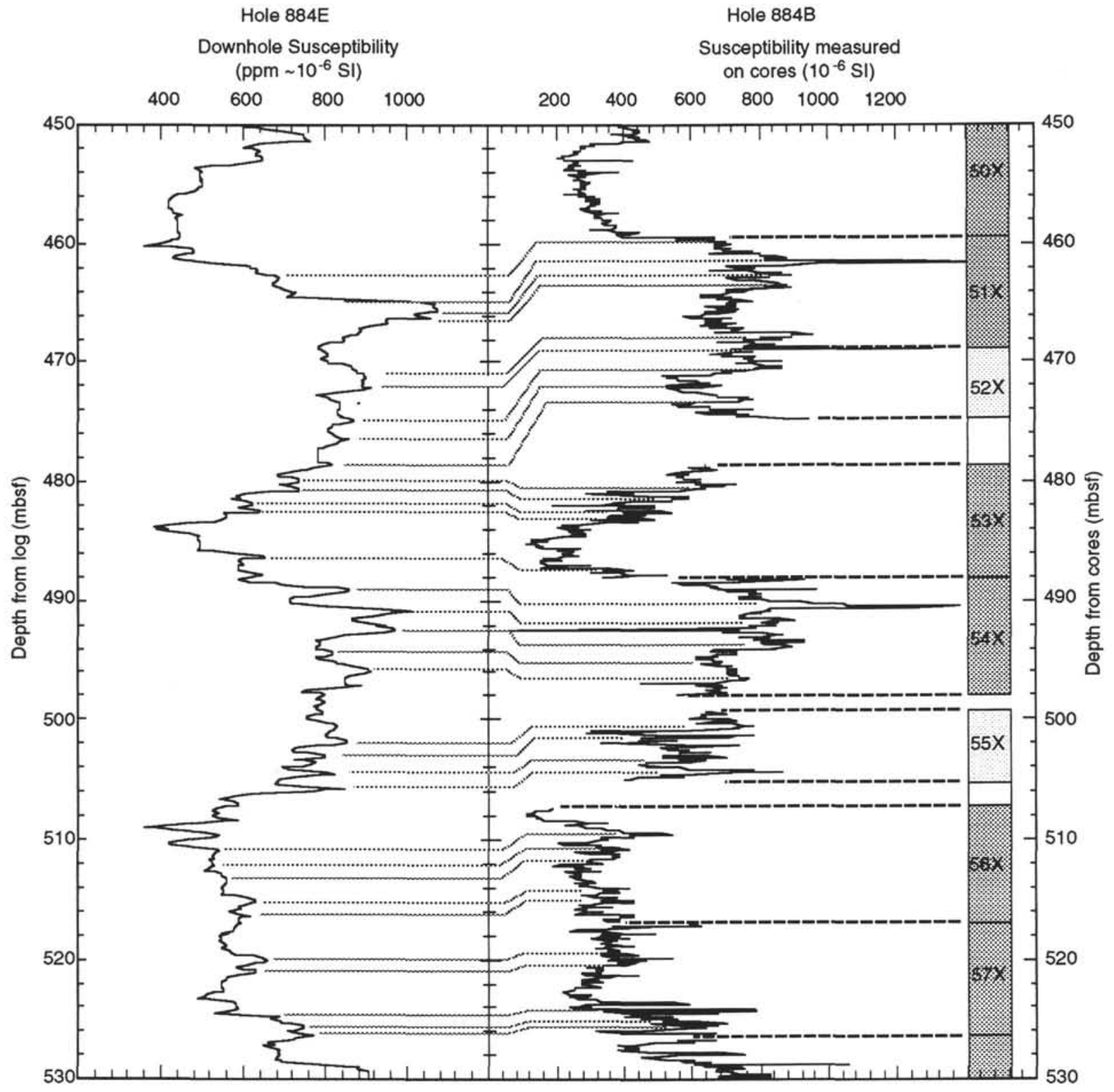

Figure 5. Comparison of the susceptibility measured by the susceptibility tool in Hole 884E with the susceptibility measured by the shipboard MST track on cores from Hole 884B. The location and recovery of the cores are also indicated. Dark gray corresponds to cores with a full recovery and data record, whereas light gray is used for cores with full recovery but for which the susceptibility record is only partial. Correlations between the two sets of data are indicated by lines.

However, there is also a contribution to magnetic susceptibility made by sediments on either side of the sensor. This will result in a characteristic smoothing of the short wavelength in the downhole log record of magnetic susceptibility, and in a thickening of the magnetic susceptibility peaks associated with thin, highly susceptible zones such as ash layers. The stratigraphic resolution of the downhole susceptibility tool is thus lower than that of the magnetic susceptibility track used on whole cores. When making correlations between the two susceptibility records this difference of resolution must be borne in mind, as well as the fact that local variations in lithology can affect the lateral continuity of the MS stratigraphy, as in Figure 4. For two closely consecutive peaks in susceptibility, the vertical resolution of the SUMT will be slightly less than $1 \mathrm{~m}$. Despite this technical limitation, many clear correlations can be made between the two records, as indicated by the correlation lines in Figure 5 . As downhole measurement is continuous, it is possible to obtain the true depth of the core directly by correlating between the two susceptibility records. The absolute depth is that given by the downhole susceptibility log with the limit of the accuracy of the logging depth. In the example shown in Figure 5 , because the bottom of the hole was collapsing, problems were encountered at Site 884 for both total induction and susceptibility, as explained above. The susceptibility log must be considered in the same way as was run 2 of the NRMT (Figure 3 ): it is a minimum depth and its relative accuracy is on the order of $1 \mathrm{~m}$, because the heave compensator was not working. For each core from Core 145-884B$51 \mathrm{X}$ to $145-884 \mathrm{~B}-57 \mathrm{X}$, four to five clear correlation lines have been drawn between the core and the downhole susceptibility records (Fig. 5). For each core, there is a more or less constant depth difference between the core and log record which, in most cases, leads to a deeper location of the correlation in the downhole log. In all cases, this depth difference changes at a core break. These features show (1) that if the heave changes the configuration of the magnetic susceptibility signal, it may not result in significant errors of depth when compared with the vertical resolution of the susceptibility tool and 
thus to the precision of the possible correlations; and (2) that problems at core breaks and double-cored zones can be investigated using the downhole susceptibility log. Because of missing material at core breaks not taken into account when calculating sub-bottom depth, the true hole depth is generally higher than the value given by drilling platform instruments. However, this depth difference will not exceed one drill pipe $(9.5 \mathrm{~m})$ so double coring will also be encountered for some cores (Ruddiman et al., 1987; Ruddiman, Sarnthein, Balduaf, 1988; Robinson, 1993). In our example, it is probable that the bottom of Cores 145-884B-52X and 145-884B-55X, and the tops of Cores 145-884B-53X and 145-884B-56X represent the same stratigraphic interval as evidenced by the comparison of core and downhole susceptibility records (Figure 5). Although several whole-core magnetic susceptibility to downhole magnetic susceptibility log correlations have been drawn on Figure 5, only one is necessary for each core if no double coring is evidenced and even if an entire cored interval shows zero recovery. Figure 6 shows the whole-core magnetic susceptibility to downhole magnetic susceptibility log correlations between Holes $884 \mathrm{~B}$ and $884 \mathrm{E}$ for the $100-200$ mbsf zone. For this depth interval, records from two holes ( $884 \mathrm{~B}$ and $884 \mathrm{C}$ ) are available and these allow correlations between susceptibility profiles, but the absolute depth is lost because of lack of recovery in both holes at about 90 mbsf as stated above. At least one clear correlation is available for each core, so the depth of all the recovered sediment can be found with respect to the logging depth.

These two examples show that a downhole susceptibility log is a useful way to reconstruct the sedimentary pile and to ascertain the relationships between consecutive cores. Furthermore, when only one hole is available, or when common gaps of recovery occurs in all holes, this method is the only one available.

\section{MAGNETOSTRATIGRAPHIC INTERPRETATION OF HOLE 884E DOWNHOLE MAGNETIC MEASUREMENTS}

As discussed in the "Principles of Measurement" section, this chapter, the magnetostratigraphic interpretation of the downhole magnetic logs first requires us to extract the induction signal of the sediment, Bf, from the total induction $\log$, and then, from $\mathbf{B f}$ to extract the remanent magnetization signal of the sediments using the susceptibility log, which is proportional to their induced magnetization. Magnetic logs were recorded at Sites 883 and 884 . All logs obtained from these sites were good from the technical standpoint; however, in each case, a problem due to the logging environment occurred to adversely affect the possible magnetostratigraphic interpretation.

At Site 883 , the magnetization of the sediments was very weak so no whole-core magnetostratigraphy was possible below $84 \mathrm{mbsf}$ (Matuyama/Gauss boundary: Rea, Basov, Janecek, Palmer-Julson, et al., 1993). During downhole magnetic logging, the sea was calm, and the heave compensator was working well. However, before drilling Hole $883 \mathrm{~F}$, where the logging runs were made, a first attempt to drill a hole dedicated to the logging operations ( $883 \mathrm{E}$ ) was done, but the lost of a bottom hole assembly (BHA) led to an abandonment of the hole. Thus, Hole $883 \mathrm{~F}$ was drilled some $20 \mathrm{~m}$ away from the abandoned one. Unfortunately, the lost BHA in Hole 883E comprised more than $100 \mathrm{~m}$ of steel pipe, which had magnetization so strong that it was clearly recorded by the magnetometer tool in Hole $883 \mathrm{~F}$. There is a clear magnetic signature of several hundred nT in the NRM log from this hole (Rea, Basov, Janecek, Palmer-Julson, et al., 1993). As the magnetization of the surrounding sediments was weak, the small errors in the calculation of the casing effect and of the BHA effect are of the same order of magnitude as the variations in the total induction due to the sediment magnetization. For this reason, we have not presented the data from Site 883 which requires more constraints from discrete sample magneto- and biostratigraphy.

For Site 884, we discussed in the "Log Quality and Technical Limitation" section, this chapter, the problems that occurred during logging (i.e., the collapsing hole and the heave compensator not working). In consequence, only one total induction $\log$ (run 1, Fig. 3) is free from problems of systematic depth distortion and both runs show slight variations in the shape of the profiles due to the lack of heave compensation during logging, despite a calm sea. Therefore, the induction related to the transient variations of the earth's field can only be estimated roughly because of the heave and because of the systematic depth difference between the two runs. However, as evidenced in Figure 3, the effect of transient variations in the Earth's field remained very low in comparison with the variations in the total induction due to the changes in magnetization of the surrounding sediments. As for the susceptibility logs, only one full log was recorded because of time constraints and the repeat section is only partially recorded. The full log shows the same problem as experienced on run 2 of the total induction log: the hole was collapsing, so the depth given by the logging unit is a minimum one, and the profile geometry is slightly deformed by the heave. The repeat log was made in order to control the changes due to thermal drift and compare these with the theoretical behavior of the tool. As this log started at a much higher level in the hole, so the depth given by the logging unit was not affected by the collapse of the bottom of the hole. For this reason, a comparison between the two susceptibility logs shows the same general characteristics as between the total induction ones (Rea, Basov, Janecek, Palmer-Julson, et al., 1993). Therefore, as noted above, the susceptibility log, like run 2 of NRMT, gives a minimum depth for a given feature in the susceptibility profile. Consequently, we have no common depth for the susceptibility and total induction logs. On future legs, this problem will no longer occur since, after Leg 145, the two sensors were combined in the same tool. A common way to compare logs recorded during different runs is to attach a common tool in all tool strings: the gamma ray. During Leg 145, because the NRMT tool was still running in analog mode, it was not possible to combine it with the gamma ray. However, despite all these problems, by using the magnetic characteristics of the sediments at Site 884, we were able to make a magnetostratigraphic interpretation of the logs obtained from Site 884 . We were able to compare this to the magnetostratigraphy obtained from whole-core pass through cryogenic magnetometer measurements, which had very good results (Rea, Basov, Janecek, Palmer-Julson, et al., 1993).

Figure 7 summarizes the magnetic logs at Site 884 . The left plot shows, in gray line, the total induction $\log$ (run 1) between 75 and 700 mbsf, with a full scale of $600 \mathrm{nT}$. As outlined in a previous section, in order to isolate the induction due to the surrounding sediments it is necessary first to estimate or measure Bt, the induction due to the transient variations of the earth's field. At Site 884 , because of the depth problems discussed above, this was not possible, but the log (Fig. 3) indicated that $\mathbf{B r}$ is very weak when compared to the anomalies related to the variation of the sediment magnetization which can clearly be seen in Figure 7. The variations in the total induction were a few meters to a few tens of meters long. Therefore, in our discussion below, we have considered that $\mathbf{B t}$ is negligible. It is also necessary to remove the other inductions that are not related to the surrounding sediment magnetization ( $\mathbf{B r}, \mathbf{B a}$, effect of the casing), as shown previously. In Figure 7, left panel, the induction that must be removed from the total induction $\log$ to isolate $\mathbf{B f}$ is shown by a thick black line. The difference between these two induction curves is shown in Figure 8 . The induction remaining is thus $\mathbf{B f}$, the induction due to the sediment total magnetization.

In order to isolate the remanent magnetization of the sediments and deduce the polarity sequence, it is necessary to use the susceptibility $\log$ and to remove its effect from the total induction log to obtain $\mathbf{B f}_{\mathbf{r}}$ (equations 1 and 2). Figure 7, right panel, shows in gray the susceptibility log in SI units (full scale is $300010^{-6} \mathrm{SI}$ ) as well as the effect of the sediment susceptibility on the magnetometer tool in nT (full scale is $600 \mathrm{nT}$, as in the total induction log on the left of Fig. 7). From Figure 7 it can be seen that the induced magnetization (proportional to susceptibility) is very weak when compared with the total 


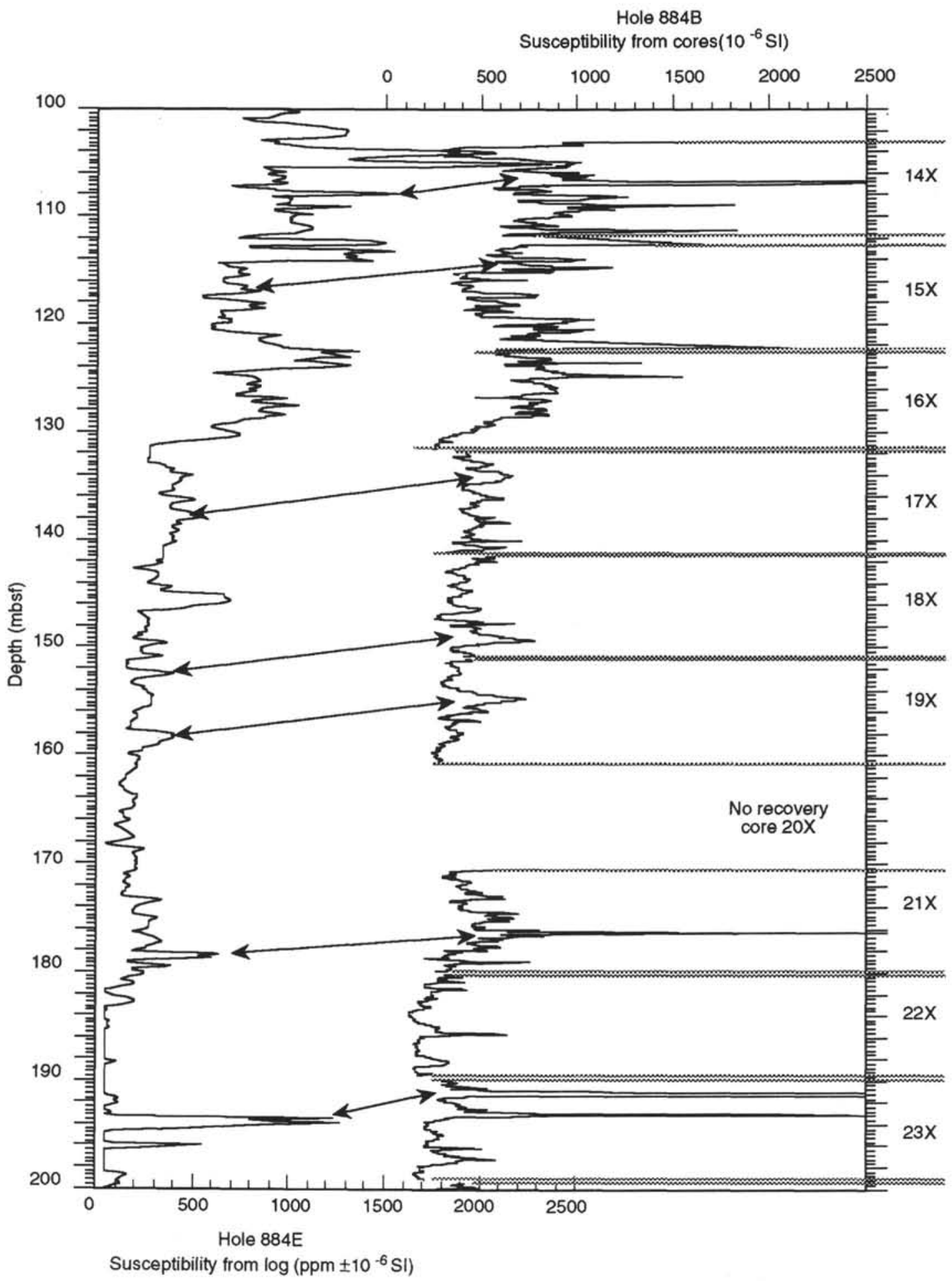

Figure 6. Comparison of the susceptibility log data from Hole $884 \mathrm{E}$ with the susceptibility measured on the cores from Hole 884B. The core limits are indicated by the horizontal gray lines. Core 145-884B-20X had no recovery. The correlations between the two records are shown by arrows.

magnetization (remanent plus induced magnetization: Figs. 7 and 8). Furthermore, its variation with depth above $650 \mathrm{mbsf}$ is also weak and will not change the algebraic sign of $\mathbf{B f}$. Because we have no common depth for the two magnetic tools, using the susceptibility run to extract the remanent magnetization from $\mathbf{B} \mathbf{f}$ will lead to large errors. However, in the case of Site 884, induced magnetization, because of the susceptibility of the sediment, is very weak when compared with the remanent magnetization. Thus, in this instance, the removal of the induction because of susceptibility will not change the algebraic sign of $\mathbf{B f}$, which can be interpreted directly in terms of the polarity of the sediment magnetization (Figs. 7 and 8).

Figure 8 shows the record of sediment magnetization, $\mathbf{B f}$, and its interpretation, for Hole $884 \mathrm{E}$. A positive value of $\mathbf{B f}$ corresponds to a normal polarity of the sediment magnetization, and a negative value to a reverse polarity. The data are only shown to a depth of 500 mbsf, as this simplification is less valid at the greater depth, and as 


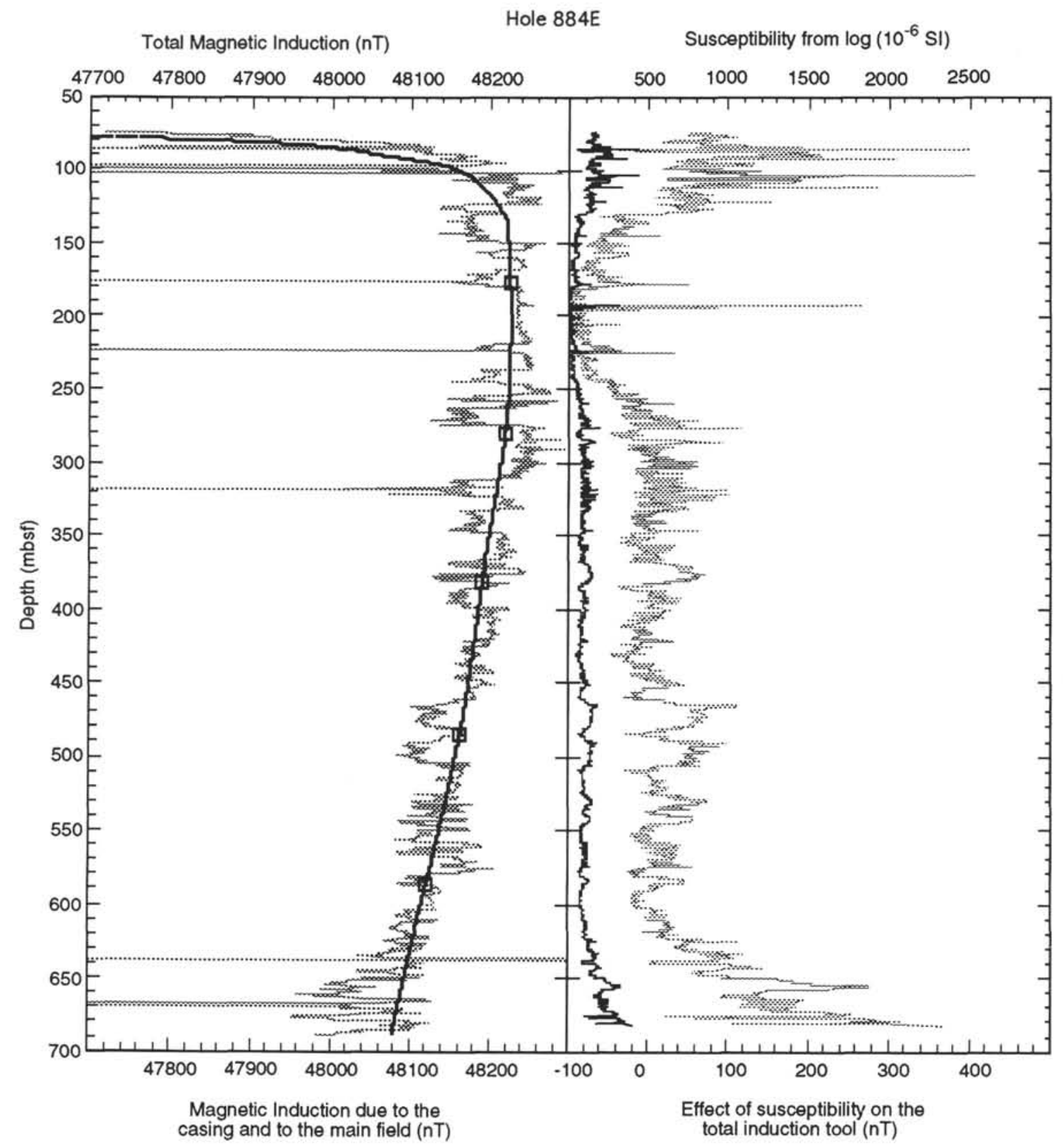

Figure 7. Summary of the magnetic logs at Site 884 and data treatment. The left panel shows the full run 1 of the magnetometer tool (gray line, full scale is 600 $\mathrm{nT}$ ) as well as the effect of $\mathbf{B r}$, the regular inner induction and $\mathbf{B a}$, the induction due to local anomalies of geologic or technologic origin (black line with square points, same scale). The right panel shows the complete susceptibility run (gray line, full scale $=3000 \times 10^{-6} \mathrm{SI}$ ) and its calculated effect on the magnetometer tool (black line, same full scale of $600 \mathrm{nT}$ as for the induction run).

condensed sections and hiatuses are suspected from biostratigraphy below 450 mbsf (Rea, Basov, Janecek, Palmer-Julson, et al., 1993). Thus, we will discuss only the results down to $450 \mathrm{mbsf}$ and wait for more complete biostratigraphic data before interpreting the magnetic logs below this depth. Figure 8 shows that many reversals can be identified in $\mathbf{B f}$, but we have to check whether they are real or not. The upper part of the interpretative column shows very recognizable features. For example, from top to bottom, the lower part of the Matuyama reversed period, the two reversed events of the Gauss normal period and the four normal events of the Gilbert reversed period. We will now discuss in detail these results and compare them with the reference geomagnetic polarity time scale of Cande and Kent (1992) and with the results obtained on board ship from the measurement of the remanent magnetization of the cores (Fig. 9).
Figure 9, right panel, shows again the data in Figure 8 but here we show also our interpretation of the magnetometer tool results. As a reference, in the center is shown the Geomagnetic polarity time scale of Cande and Kent (1992). The left part of Figure 9 shows the inclination of the remanent magnetization between 0 and $600 \mathrm{mbsf}$, as it was determined on board ship from the cores after they were subjected to an alternating field demagnetization of $15 \mathrm{mT}$ (Rea, Basov, Janecek, Palmer-Julson, et al., 1993). This value for peak AF demagnetizing field was the highest permitted on board ship for measurements made on whole cores. During the leg, we made numerous measurements on discrete samples using a higher value for the peak $\mathrm{AF}$ demagnetizing field ( 30 to $40 \mathrm{mT}$ ), in order to check if a $15 \mathrm{mT}$ value was sufficient to determine the stable magnetization of the sediments. All the measurements we made on discrete samples show 
that the late remagnetization related to the coring process is removed after a $15 \mathrm{mT}$ demagnetization, and that the characteristic primary magnetization of the sample is found when such a magnetization does exist. In some cases the sample does not bear a stable magnetization. Some of the peaks in positive inclination that are not interpreted in terms of a reversal in Figure 9 have been correlated with a normal remagnetization of such unstable samples inside the cryogenic magnetometer. Thus, the inclination of the remanent magnetization shown in Figure 9 can be interpreted in terms of a primary magnetization acquired during sedimentation under the earth's field, and the polarity changes are related to the reversals of this field. The interpretation of this inclination record has thus been made by reference to the polarity time scale and the correlations shown in Figure 9 between the inclination plot and the Cande and Kent (1992) scale are those determined on board ship (Rea, Basov, Janecek, Palmer-Julson, et al., 1993). On the right panel of Figure 9, we have represented the correlations between the geomagnetic time scale and the sequence of reversals deduced from the magnetometer tool.

As Figure 9 contains a great deal of information, we will discuss it in two parts. First, we will discuss the results of the tool magnetostratigraphy and compare these with the results obtained from cores, concentrating on the zones where the tool data add more information. Second, we will discuss, in more detail, the records themselves, comparing some details from the core inclination record with the $\mathrm{Bf}$ record. These comparisons show that, even when these records are not clearly consistent with the polarity time scale, the two sets of data are consistent in respect to each other.

For clarity, we will discuss only the normal events from top to bottom. The youngest normal zone that is recognized in the record derived from the NMRT is the Olduvai $\mathrm{C} 2 \mathrm{n}$ event (1.757-1.983 Ma). As the upper part of the hole was cased by the drill pipes, it was not possible to see the Bruhnes $\mathrm{C}$ In period or the Jaramillo C1n. In event. However, the depth of the shallowest Olduvai normal event derived from the tool magnetostratigraphy is consistent with the depth of the base of this same event in the record from core measurements, and with the susceptibility core-log correlations discussed previously. As intervals of no recovery occurred in both Holes $884 \mathrm{~B}$ and $884 \mathrm{C}$ at the level of the top of the Olduvai event, no composite depth was available, and the depth of the termination of this event was unknown. The magnetic log, being continuous, contained this information. The short normal event located below the Olduvai one is the C2r. In Reunion 1 (2.197-2.229 Ma) event which was already recognized from core measurements. The short (2.42-2.441 Ma) Reunion 2 event has not been found in the records of either measurement. Its duration was probably too short to be detected considering the average sedimentation rate.

Between 120 and $180 \mathrm{mbsf}$, the three normal polarity intervals of the Gauss period are very clear (C2An. $1 n$ : $2.6-3.054 \mathrm{Ma}$; $22 \mathrm{An} .2 \mathrm{n}$ : 3.127-63.221 Ma; C2An.3n: 3.325-3.553 Ma). In Hole 884B the total lack of recovery for Core $20 \mathrm{X}$ did not allow the determination of the depth of the top of event C2An.3n, whereas the log provides this information (this boundary was recognized from the data of $884 \mathrm{C}$ (Rea, Basov, Janecek, Palmer-Julson, et al., 1993) but no composite depth is available.

Between 180 and $310 \mathrm{mbsf}$, the depths of the four normal intervals of chron C3 (C3n.1n: 4.033-4.134 Ma; C3n.2n: 4.265-4.432 Ma; C3n.3n: 4.611-4.694 Ma; C3n.4n: 4.812-5.046 Ma) are clearly identified in the logs. Because of poor recovery, only the limits of the first and the last normal interval were available from Hole $884 \mathrm{~B}$ core measurements.

Between 310 and $365 \mathrm{mbsf}$, both core and log measurements show the depth of the limits of the two normal intervals of chron $\mathrm{C} 3 \mathrm{~A}$ (C3An.1n: 5.705-5.946 Ma; C3An.2n: 6.078-6.376 Ma).

Between 365 and 372 mbsf, two small normal intervals are identifiable in the logs. When compared with the Cande and Kent (1992) geomagnetic time scale and with the core measurements, they probably correspond to the last two normal intervals of chron C3B (C3Bn: 6.744-6.901 Ma; C3Br.1n: 6.946-6.981 Ma). Without further analy-

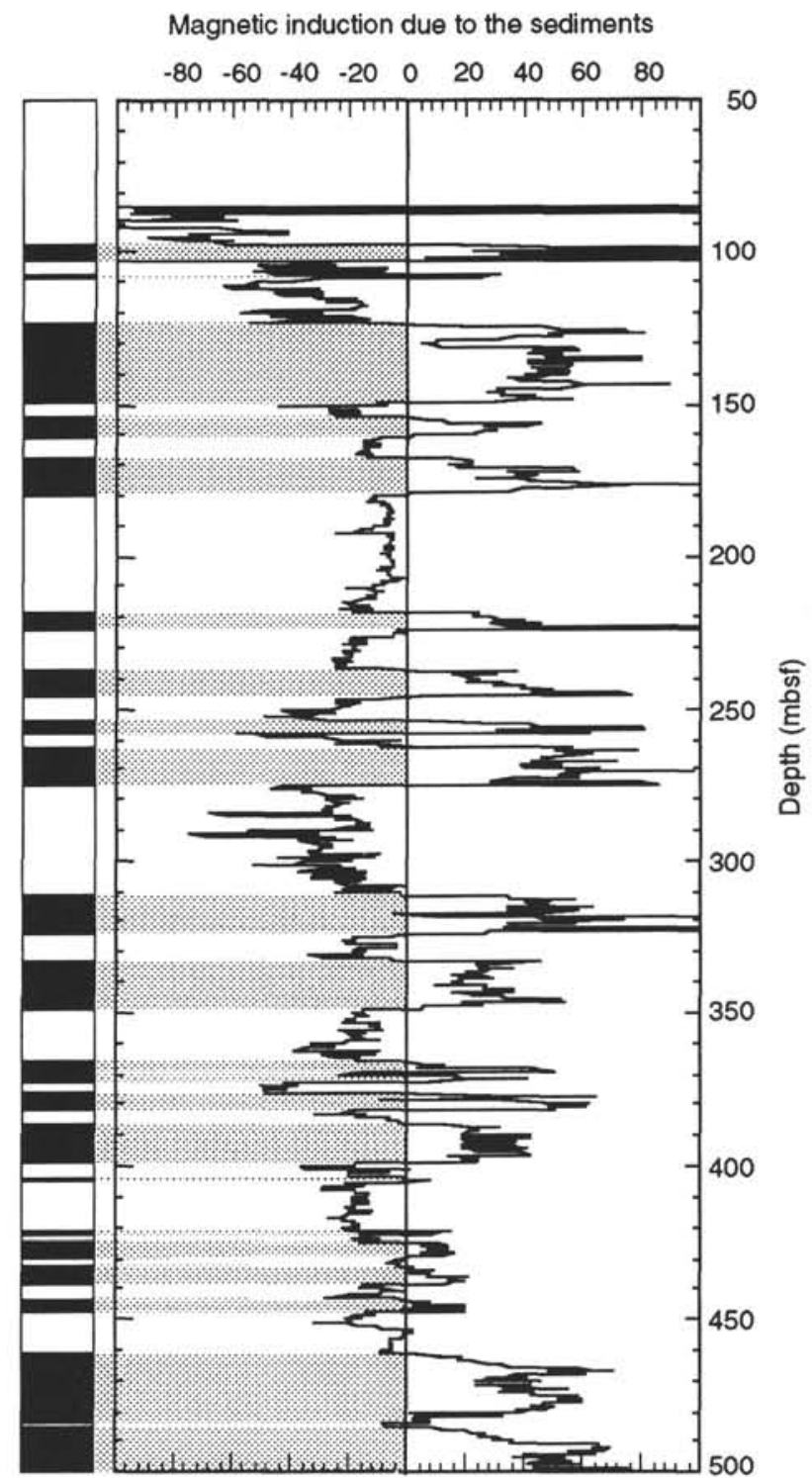

Figure 8. Induction $\mathbf{B f}$ caused by the sediments in Hole 884E, as deduced from the total induction magnetometer run and interpretation in terms of polarity changes of the Earth's field during sediment deposition. The positive values of $\mathbf{B f}$ relate to a normal direction of the Earth's field; the negative values relate to a reverse direction. Gray areas correlated to black zones show the normal polarity interval deduced from the log.

sis, both methods show no evidence of the older, very short normal event C3Br. $2 n(7.153-7.187 \mathrm{Ma})$. A reason could be the low sedimentation rate of about $20-25 \mathrm{~m} / \mathrm{m}$.y. inferred for that period. If this event is marked in the sediments by a change of remanent magnetization polarity, it would be 0.6 to $0.75 \mathrm{~m}$ thick, which is at the vertical resolution limit of the tool and is thus difficult to see in the log. A high drilling disturbance in Core 145-884B-42X, Section 2-80 cm to Section 3-100 cm caused these data to be rejected for the core magnetostratigraphy (Rea, Basov, Janecek, Palmer-Julson, et al., 1993). Thus, a short reversal may exist between 375 and $376.8 \mathrm{mbsf}$ (core depth). Such a reversal can be correlated with the existence of a very narrow zone at 378-378.6 mbsf (log depth) where Bf is slightly below zero. In the light of these two observations, another explanation is that event C3Br.2n (34 k.y. long) is present in the sediment magnetization record. Thus, as shown in Figure 9, the first $1.3 \mathrm{~m}$ of the $376.7-382$ mbsf negative value of $\mathrm{Bf}$ will correspond to this short event, and that 


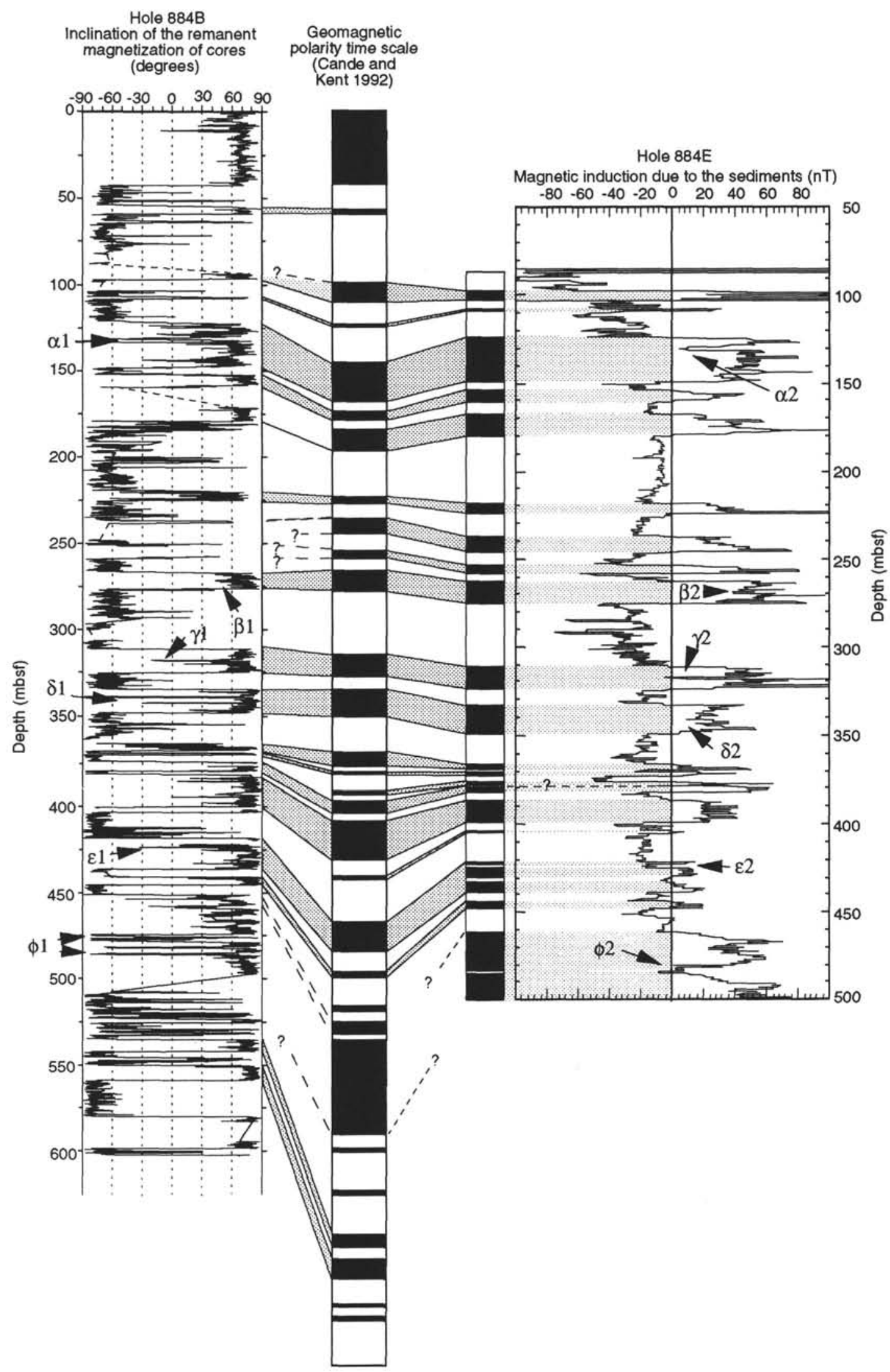

Figure 9. Magnetostratigraphic interpretation of the magnetometer log and comparison with core data. On the right panel is the induction due to the sediments and the deduced polarity. On the left panel is the inclination of the whole core remanent magnetization after a $15 \mathrm{mT}$ alternative field demagnetization. At the center is the Cande and Kent (1992) geomagnetic polarity time scale as well as the correlations made with the two data sets. The labelled points of the curves are discussed in the text. 
its lower part (378.6-382 mbsf tool depth) corresponds to the last normal event of chron 4 (C4n.1n: 7.245-7.376 Ma). However, it must be stated that the difference between these two possibilities (absence of C3br.2n, as in Figure 8, or its presence, as in Figure 9) is at the vertical resolution limit of the tool.

Whatever the true explanation is, the log data show that between about $376 / 378$ and 405 mbsf, the three normal intervals of chron 4 are recognized (C4n.1n: 7.245-7.376 Ma; C4n.2n: 7.464-7.892; C4r. In: $8.047-8.079)$. The later interval was not recognized from core magnetostratigraphy, although this may be because of a 70-cm-long gap in the data: Section 145-884B-44X-7 was too short to be measured and the first data from Core 145-884B-45X was $70 \mathrm{~cm}$ below the lowermost measurement made on Core 145-884B-44X.

Between 420 mbsf and $450 \mathrm{mbsf}$, the tool data identify four normal intervals. Their interpretation is not easy, but, by comparison with the core data and with the biostratigraphy (Rea, Basov, Janecek, Palmer-Julson, et al., 1993), we consider that the three shallower ones correspond to the C4An event (8.529-8.861 Ma) and the deepest one to the C4Ar.1n event (9.069-9.149 Ma). From biostratigraphy, a hiatus is suspected at around $440 \mathrm{mbsf}$ (core depth). This could explain the absence of the oldest C4A normal chron (C4Ar.2n:9.4289.491), and that of the top of chron C5 (C5n.1n: 9.592-9.735). Diatom stratigraphy (Rea, Basov, Janecek, Palmer-Julson, et al., 1993) suggests a possible hiatus between 8.4 and $9.8 \mathrm{Ma}$, which is in agreement with the absence of these two normal intervals. Thus, the large zone of normal magnetization, determined from both log and core, would correspond to the C5n.2n event (9.777-10.834 Ma), but its limits are still uncertain.

Another interesting result shown in Figure 9 is that the inclination of the core and the values of Bf determined from the NRMT show some common features labelled $\alpha 1-\alpha 2, \beta 1-\beta 2$, for example, for ease in reference below. These common features tend to support our magnetostratigraphic interpretation, and we will show that the tools are sensitive to small changes in sediment magnetization.

The C2An. In normal event located at about 120-150 mbsf does not contain any reversed episode according to geomagnetic polarity time scales. However, in the core inclination record, an apparent reversed zone can be distinguished $(\alpha 1)$. This zone is correlated with an important decrease in $\mathrm{Bf}(\alpha 2)$ and can also be recognized at Site 883. The measurement of a sample from the latter site has shown that it has a very unstable and weak magnetization. This was probably recorded in the Site 884 downhole $\log$ as a decrease in the rock magnetization. Valet and Meynadier (1993) in a paleointensity study of the earth's field based on data from ODP Leg 138 have found an important decrease in the field intensity in the upper part of this normal event. The two observations from Sites 883 and 884 may be related to such a low in the field intensity.

For three normal intervals in the inclination record of Hole 884B, a decrease in the declination may be seen inside the polarity interval C $3 n .4 n(\beta 1), C 3 A n .1 n(\gamma 1)$ and C3An.2n ( 81$)$. In the log, a similar feature can also be seen as a decrease in $\mathrm{Bf}$, that is, a magnetization decrease $(\beta 2 ; \gamma 2 ; \delta 2)$. In one case (d) both the cores and the log suggest a short reversed event.

We noted above that the logs did not suggest a single polarity for the C4An normal period but rather three short normal periods separated by two short reversed ones. Once again, (points $\varepsilon 1, \varepsilon 2$ ), the core data also suggest a similar feature for the shallowest short reversed period.

Finally, the large zone interpreted as the long C $5 n .2 n$ normal period contains an unexpected short reversed zone, which is present in both the inclination record from the cores $(\phi 1)$, and in the log magnetization record $(\phi 2)$.

It is beyond the scope of this paper to decipher new polarity events or paleosecular variations of the strength of the earth's field. However, the above correlations between the paleomagnetic inclination record from cores and the induction log from the downhole magnetometer tool support the conclusion that, in this case, the log is mostly governed by the rock remanent magnetization. Thus the induction log can be interpreted directly in terms of changes in the polarity of the rock magnetization.

Figure 10 shows the age-depth curves based on the magnetostratigraphic data from the cores (diamonds) and from the log (open squares). As indicated clearly in Figure 9, the two sets of data agree very well, and the log curve is more complete. As a result of the hole conditions during run 1 of the magnetometer tool at Site 884, we feel that the value of depth given by the tool is probably more accurate (it is generally deeper, as expected), but that there is an uncertainty of the order of $1 \mathrm{~m}$ for this depth determination.

\section{CONCLUSIONS}

The use of downhole magnetic logging during Leg 145 has been a success, particularly in terms of quality of the logs obtained. We have found that log quality is more related to the logging conditions than to the quality of the tools themselves. The logging tools can, even in the best cases (Site 883), be sensitive to the limitations of the logging unit itself.

The fundamental value of these magnetic logs is that, as with all logs, they are continuous and are not limited by core recovery. Thus, any information given by a log will be the only data available for zones of poor or no recovery, or to estimate the importance of the lost intervals between two successive cores and the importance of the double-cored zones.

As susceptibility is very sensitive to variations in composition of the sediments, it is a useful tool for making correlations from one hole to another and, in some cases, from one site to another, as has been demonstrated in previous studies. Thus, on board ship, it is used to identify gaps in the sedimentary record of one hole with the help of a nearby second hole, in order to estimate the true thickness of the sedimentary pile. We have shown that because downhole susceptibility logging is continuous and is done from the bottom of the deepest hole at a given site, it will give information on the true sedimentary pile even for depths where only one cored hole is available. The downhole susceptibility log also provides a record of the sedimentary sequence for intervals of no recovery. Finally, even in intervals where double-cored holes are available, gaps caused by lack of recovery may occur at the same level in both holes so that any information on the true depth can be lost. This problem occurred at Site 884 , where the downhole susceptibility log allowed us to estimate the composite depth and to reconstruct the true thickness of the sedimentary pile.

However, with regard to the systematic use of this $\log$ as a routine tool in paleoceanographic legs, two problems may occur. The susceptibility logs are dependent on the quality of the logging unit and, in particular, on the heave compensator and hole conditions. Regardless of what tools are deployed on future legs, this limitation will always remain. Another point is the quality of the correlations between the downhole susceptibility logs and the shipboard whole-core susceptibility records. There is a significant difference in the resolution of the shipboard magnetic susceptibility records and the downhole magnetic susceptibility logs. A lower resolution will always characterize the magnetic susceptibility tool used in Leg 145, which, in most cases (Pozzi et al., 1993), is necessary to combine with the total induction tool for the magnetostratigraphic interpretation of the logs. A future priority in the ODP environment might be to add a high-resolution susceptibility sensor, mounted on a pad like the FMS tool, in order to get a response close to the Bartington system and the MST track on the ship. This would allow a better correspondence between the two MS records. Such an infracentimetric sensor has already been produced in one of our laboratories (LETI) as a research device.

The magnetometer tool has allowed us to obtain a very precise magnetostratigraphy down to $450 \mathrm{mbsf}$ ( $\sim 8 \mathrm{Ma}$.). A comparison with the data obtained from cores shows a very good agreement between the two sets of data. Furthermore, the log provided quite a lot of information in the intervals of no recovery, or where drilling-induced core disturbances were too great to get a good remanent magnetiza- 


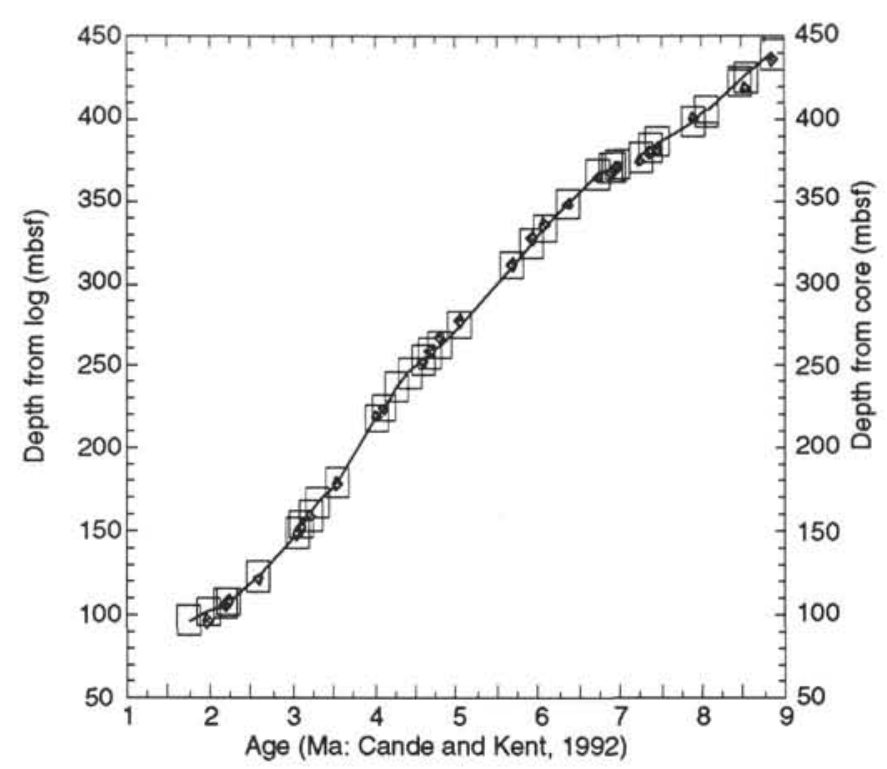

Figure 10. Age-depth curves for Site 884 as deduced from whole-core measurements (diamonds) and from the induction $\log$ (squares connected by lines).

tion signal. In the case of Leg 145, we were fortunate that the remanent magnetization of the sediment was very high compared with its susceptibility. Because of hole stability problems, the depth of the susceptibility log was minimal, so it was difficult to match the magnetic susceptibility and induction records. However, this is no longer a problem as the two tools are now combined in one, and, as they are both digital, they can be mounted in a tool string with the gamma ray. Thus, in future, we will at least obtain a common depth for the two magnetic logs and be able to compare them with other logs via the gamma ray record.

\section{ACKNOWLEDGMENTS}

G. Dubuisson would like to thank the Leg 145 scientific party for these two very interesting and enjoyable months together on board the JOIDES Resolution. The authors would like to thank J.F. Allan and S.G. Robinson for their very constructive reviews that helped to improve the original manuscript. S.G. Robinson also did a very good job helping us with the English of this paper, thank you. Participation in Leg 145 was funded by ODPFrance and by a grant from the French national program "Géosciences Marines".

\section{REFERENCES}

Backman, J., Duncan, R.A., et al., 1988. Proc. ODP, Init. Repts., 115: College Station, TX (Ocean Drilling Program).
Barthès, V., 1990. Modélisation magnétique en forage. Rap. CEA/LETI/DSYS/ SETIA, 90-59.

Bloemendal, J., King, J.W., Tauxe, L., and Valet, J.-P., 1989. Rock-magnetic stratigraphy of Leg 108 Sites $658,659,661$, and 665 , eastern tropical Atlantic. In Ruddiman, W., Sarnthein, M., et al., Proc. ODP, Sci. Results, 108: College Station, TX (Ocean Drilling Program), 415-428.

Bloemendal, J., Tauxe, L., Valet, J.-P., and Shipboard Scientific Party, 1988. High-resolution, whole-core magnetic susceptibility logs from Leg 108. In Ruddiman, W., Sarnthein, M., Baldauf, J., et al., Proc. ODP, Init. Repts., 108: College Station, TX (Ocean Drilling Program), 1005-1013.

Cande, S.C., and Kent, D.V., 1992. A new geomagnetic polarity time scale for the Late Cretaceous and Cenozoic. J. Geophys. Res., 97:13917-13951.

Cochran, J.R., Stow, D.A.V., et al., 1989. Proc. ODP, Init. Repts., 116: College Station, TX (Ocean Drilling Program).

Mascle, A., Moore, J.C., et al., 1988. Proc. ODP, Init. Repts., 110: College Station, TX (Ocean Drilling Program).

Ocean Drilling Program, 1990. Shipboard Scientist's Handbook (rev. ed.). ODP Tech. Note, 3 .

Peirce, J., Weissel, J., et al., 1989. Proc. ODP, Init. Repts., 121: College Station, TX (Ocean Drilling Program).

Pozzi, J.-P., Barthés, V., Thibal, J., Pocachard, J., Lim, M., Thomas, T., and Pages, G., 1993. Downhole magnetostratigraphy in sediments: comparison with the paleomagnetism of a core. J. Geophys. Res., 98:7939-7957.

Prell, W.L., Niitsuma, N., et al., 1989. Proc. ODP, Init. Repts., 117: College Station, TX (Ocean Drilling Program).

Rangin, C., Silver, E.A., von Breymann, M.T., et al., 1990. Proc. ODP, Init. Repts., 124: College Station, TX (Ocean Drilling Program).

Rea, D.K., Basov, I.A., Janecek, T.R., Palmer-Julson, A., et al., 1993. Proc. ODP, Init. Repts., 145: College Station, TX (Ocean Drilling Program).

Robinson, S.G., 1993. Lithostratigraphic applications for magnetic susceptibility logging of deep-sea sediment cores: examples from ODP Leg 115. In Hailwood, E.A., and Kidd, R.B. (Eds.), High Resolution Stratigraphy. Spec. Pap.-Geol. Soc. Am., 70:65-98.

Ruddiman, W.F., Cameron, D., and Clement, B.M., 1987. Sediment disturbance and correlation of offset holes drilled with the hydraulic piston corer: Leg 94. In Ruddiman, W.F., Kidd, R.B., Thomas, E., et al., Init. Repts. DSDP, 94 (Pt. 2): Washington (U.S. Govt. Printing Office), 615-634.

Ruddiman, W., Sarnthein, M., Baldauf, J., et al., 1988. Proc. ODP, Init. Repts., 108 (Sections 1 and 2): College Station, TX (Ocean Drilling Program).

Valet, J.-P., and Meynadier, L., 1993. Geomagnetic field intensity and reversals during the past four million years. Nature, 336:234-238.

\footnotetext{
- Abbreviations for names of organizations and publications in ODP reference lists follow the style given in Chemical Abstracts Service Source Index (published by American Chemical Society).
}

Date of initial receipt: 5 April 1994

Date of acceptance: 1 September 1994

Ms 145SR-135 